\title{
An Excel-based index (PestEX) for environmental mobility of pesticides in relation to water resources
}

\author{
N. Z. Jovanovic \& C. Petersen \\ CSIR, Natural Resources and Environment, South Africa
}

\begin{abstract}
Agriculture is one of the main sources of non-point source (NPS) pollution in South Africa. Research was therefore initiated on the development of an integrated modelling framework for prediction of agricultural NPS pollution from field to catchment scale. In that context, an Excel-based Pesticide Environmental indeX (PestEX) was developed that accounts for the main factors affecting mobility of pesticides and their potential for landing up in a water resource. A tiered approach was used to combine these factors based on their level of occurrence, namely local scale (pesticide drift; position of application in relation to streams and groundwater; general slope of the area; presence of impervious layers in soils and dominant flow direction; tillage practices; soil hydraulic properties; the impact of irrigation practices/rainfall distribution via overland flow and deep percolation; the presence of anti-erosion contours), catchment scale (pesticide properties like sorption, volatilization and decay; the presence of wetlands/buffer strips) and overarching level (pesticide application; sensitivity of the receiving environment). Each of these factors is assigned a rating (using fuzzy logic for numerical variables) and weighting to produce a pesticide mobility score. The normalized score allows comparison and minimization of environmental and pollution abatement costs. The PestEX calculator was demonstrated using data from an experimental site in the Western Cape (South Africa), where methomyl and tebuconazole were applied to dryland wheat, and their mobility to water bodies was scored. Potential users of this tool are the scientific community, farmers, pesticide consultants and the regulatory authority. Possible applications are in comparative analyses of environmental and pollution abatement costs of different chemicals for regulatory or marketing purposes, sensitivity analyses to assess the effects of different mitigation/
\end{abstract}


management measures (e.g. size of wetlands to be constructed), minimization of costs by changing mitigation/management practices etc.

Keywords: environmental cost, environmental mobility, fuzzy logic, index, mitigation measures, non-point source pollution, pesticides, pollution abatement cost, water resources.

\section{Introduction}

Agriculture and rural settlements were identified as the main non-point sources of pollution in South Africa [1]. Research was therefore initiated by the Water Research Commission (Pretoria, South Africa) on the development of an integrated modelling framework for prediction of agricultural non-point source (NPS) pollution from field to catchment scale. The pollutants considered in this research were nutrients, sediments, heavy metals and pesticides. Other types of pollution, e.g. salinity and microbiological, were dealt with in separate research programmes. The focus of this paper is on guidelines for the estimation of environmental mobility of pesticides, as support to the integrated modelling framework for agricultural NPS pollution.

Environmental impacts resulting from the use of pesticides can be predicted with process-based simulation models [2]. However, Boesten [3] pointed out difficulties in the application and validation of such models. Some of the problems are the complexity of the soil-plant-atmosphere system, large amount of input data required, lack of knowledge on pesticide behaviour and toxicity as well as spatial and temporal uncertainties. An alternative to process-based models is the use of expert systems. These are generally interactive computer programmes that include quantitative informational databases and qualitative knowledge, experience and judgement gained over many years of work and research. The output of expert systems is often expressed in the form of simple environmental performance indicators or indexes $[4,5]$.

Environmental costs are not always considered in environmental studies because of the difficulties in assigning costs to indirect (external) economic values. Environmental impact indicators also seldom consider mitigation/ management practices and different scales of impact. In this study, we developed a Pesticide Environmental indeX (PestEX) that accounts for the main factors affecting the contamination of surface- and groundwaters, including the effects of mitigation/management measures. The novelty of the approach is that the factors were combined based on their effects at different scales. In addition, fuzzy logic normalization of the factors allows comparison and minimization of environmental and pollution abatement costs. The main purpose of PestEX is to assess the mobility of pesticides and their potential for landing up in a water resource, and therefore the exposure potential to the aquatic environment. 


\section{Description of PestEX}

\subsection{Conceptual model}

The conceptual model of PestEX is shown in fig. 1. All factors considered in the assessment of the environmental mobility of pesticides are shown on the left side in fig. 1. The first group of factors, or local scale inputs, are those related to site specific conditions and management practices, namely: drift of pesticides at application (e.g. by tractor spraying or aircraft), position of application in relation to streams and groundwater, general slope of the area, dominant flow direction (horizontal or vertical) due to the presence of impervious layers in soils, tillage practices, soil hydraulic properties (saturated hydraulic conductivity), irrigation practices/rainfall distribution via overland flow and deep percolation, and the presence of anti-erosion contours. Each of these factors is assigned a rating and weighting to produce a score. The scores are then averaged into a combined local scale score (fig. 1).

The second group of factors, or catchment scale inputs, are represented by pesticide properties and the presence of wetlands/buffer strips. These factors are placed at a higher tier compared to the local scale factors because the processes depending on pesticide properties (volatilization, sorption and decay) occur at both local and catchment scale (at any position along the pathways of chemicals towards waters), whereas wetlands and buffer strips generally serve an area larger than individual farms and fields (local scale), and they are generally located in proximity of streams. The catchment scale factors are assigned a rating, weighted and averaged together with the combined local scale score, to produce a combined local+catchment scale score (fig. 1).

The third group of factors are overarching inputs. Pesticide application represents the source of pollution, whilst environmental sensitivity gives an indication of the sensitivity of the receiving environment. Regardless of all other inputs, high pesticide applications (expressed either as rate or volume) will tend to increase the effects on the environment, whilst no pesticide application will result in no effects. Similarly, the presence of organisms that are more sensitive to pollution will tend to increase the impact on the receiving environment, whilst the presence of organisms that are tolerant to pollution will result in no exposure of the receiving water body. Pesticide application and environmental sensitivity are assigned a rating, weighted and combined with the score of all other factors to produce a combined score (fig. 1).

Rating and scoring is done separately for surface- and groundwater. So, two combined scores are produced, the one for surface water and the other for groundwater. These are then weighted depending on water usage. A higher weighting is assigned to surface water if this is the dominant or the only water source for consumption, and viceversa. Finally, the scores for surface- and groundwater are combined to produce an environmental score (fig. 1). One of the overarching factors included in the environmental score, namely pesticide application, also affects the economic yield. A higher pesticide application 
results in a smaller yield reduction (the trade-off being a higher environmental cost) and viceversa (fig. 1).

All scores are normalized from 0 to 1 . An environmental score of 0 indicates the pesticide is unlikely to reach and have an effect on waters, whilst 1 corresponds to maximum environmental mobility. An economic score of 0 corresponds to maximum yield and profit, whilst an economic score of 1 represents total crop loss. The normalization was done in order to facilitate the comparison and optimization (minimization) of environmental and economic scores, as well as the translation of scores into real cost values.

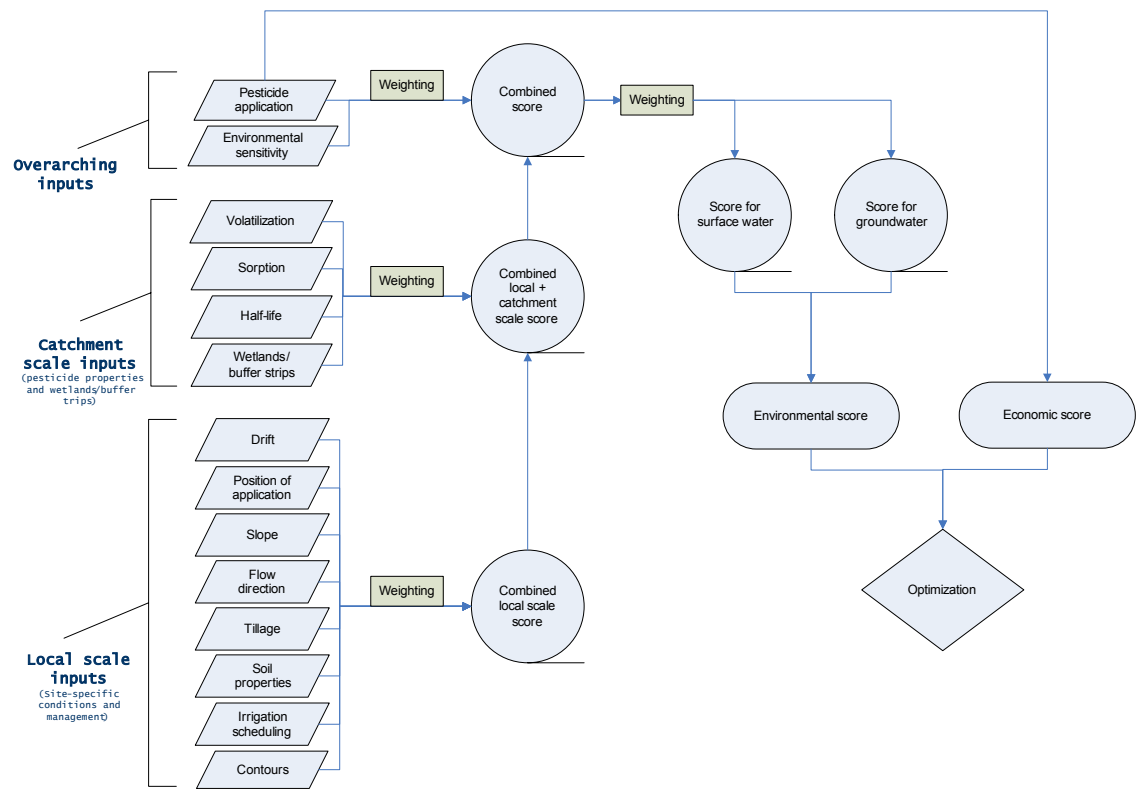

Figure 1: $\quad$ Flow diagram of the Pesticide Environmental indeX (PestEX).

\subsection{Scoring system}

Each factor is represented by a numerical or boolean variable. Numerical variables are assigned two values based on expert knowledge, the one corresponding to the maximum rating (1) and the other representing the minimum rating (0). Three categories of ratings are therefore defined for each numerical variable, namely low, medium and high (table 1). For example, the drift factor is expressed through the variable drift percentage, or the pesticide rate drifting and reaching surface water as percentage of intended rate of field application. The drift rating is applied only to surface water, and it depends on 
distance to stream, application technique (e.g. aircraft or spraying by tractor), crop structure and cover as well as wind speed. A drift of $0 \%$ causes no effects on waters (0), whilst a drift of $1 \%$ results in maximum rating (1). The rating of any drift between 0 and $1 \%$ is determined using fuzzy logic, based on the concept of partial truth that is commonly applied when categories of natural variables are defined to deal with uncertainties [6]. In conventional set theory, an element can be either member or non-member of a set. In fuzzy set theory, elements can have a degree of membership, or be partial members of one or more sets. For example, a drift of $0 \%$ belongs entirely to the low rating category, whilst a drift of $1 \%$ belongs entirely to the high rating category. A drift of $0.75 \%$ belongs partially to the high rating category (75\%) and partially to the low rating category $(25 \%)$. This can be described with a function, for this particular example the straight line in fig. 2. Under natural conditions, changes between categories of variables do not generally occur abruptly, so the straight line representing the degree of membership was smoothed out using a Betacumulative distribution function (fig. 2). A similar approach is used for the other variables and their rating categories in table 1.

Boolean variables in PestEX are flow direction, tillage practices and contours (table 2). Categorization of boolean variables is opposite for surface water and groundwater. The magnitude of the effects can be adjusted through weighting.

\subsection{Interface}

PestEX is an Excel-based, interactive programme. A snapshot of the Main Menu of the programme is shown in fig. 3. One worksheet is dedicated to the input and calculation of each factor and it can be accessed by clicking on the relevant command button in the Main Menu. Any factor can be disabled by clicking on the tick-box (fig. 3). The programme makes extensive use of pop-up comments to facilitate the user in operating the programme as well as selecting the inputs. The graphs are interactive and they automatically show input data and ratings, as in the example in fig. 2. Links to databases, reviews and references are available within the programme:

- A database of properties of more than 2,000 chemicals [10]. The database also provides links to web sites where extensive information on individual chemicals is available.

- List of macroinvertebrates from the River Health Programme SASS 5 (South African Scoring System version 5) score sheet and sensitivity ratings [9].

- A review of measures and their effectiveness in mitigation of pesticide impacts on waters, including wetlands and buffer strips.

- A review of models that can be used to predict the environmental impact of pesticides.

Nearly-linear relationships described with fuzzy logic could be easily substituted with non-linear functions, should these be available. For example, the relationship between yield reduction and pesticide application cannot always be 
Table 1: $\quad$ Range of variables and rating categorization for numerical input variables in PestEX.

\begin{tabular}{|c|c|c|c|c|}
\hline \multirow{2}{*}{ Input factor } & \multirow{2}{*}{ Variable } & \multicolumn{3}{|c|}{ Ranges for rating categories } \\
\hline & & Low & Medium & High \\
\hline Drift & Drift percentage $(\%)^{1,2}$ & 0 & $0-1$ & $>1$ \\
\hline \multirow{2}{*}{$\begin{array}{l}\text { Position of } \\
\text { application }\end{array}$} & $\begin{array}{l}\text { Distance from stream }(\mathrm{m}) \\
\text { for surface water }\end{array}$ & $>1000$ & $0-1000$ & Next to stream \\
\hline & $\begin{array}{l}\text { Groundwater depth (m) } \\
\text { for groundwater }\end{array}$ & $>30$ & $5-30$ & $<5$ \\
\hline Slope & Slope $(\%)^{3}$ & $<2$ & $2-5$ & $>5$ \\
\hline Soil properties & $\begin{array}{l}\text { Saturated hydraulic } \\
\text { conductivity }\left(\mathrm{m} \mathrm{d}^{-1}\right)^{3,4}\end{array}$ & $>\log 7.128$ & $\begin{array}{c}\log 0.0048- \\
\log 7.128\end{array}$ & $<\log 0.0048$ \\
\hline \multirow{2}{*}{$\begin{array}{c}\text { Irrigation } \\
\text { scheduling } \\
\text { /rainfall } \\
\text { distribution }\end{array}$} & $\begin{array}{l}\text { Overland flow }\left(\mathrm{mm} \mathrm{a}^{-1}\right) \\
\text { for surface water impact }\end{array}$ & $<50$ & $50-550$ & $>550$ \\
\hline & $\begin{array}{c}\text { Deep percolation }\left(\mathrm{mm} \mathrm{a}^{-1}\right) \\
\text { for groundwater impact }\end{array}$ & $<50$ & $50-550$ & $>550$ \\
\hline Volatilization & Henry Law's constant ${ }^{1}$ & $>\log 2.65 \mathrm{E}-4$ & $\begin{array}{c}\log 2.65 \mathrm{E}-6- \\
\log 2.65 \mathrm{E}-4\end{array}$ & $<\log 2.65 \mathrm{E}-6$ \\
\hline Sorption & $\begin{array}{c}\text { Organic carbon partition } \\
\text { coefficient }\end{array}$ & $>\log 634000$ & $\begin{array}{l}\log 0.001- \\
\log 634000\end{array}$ & $<\log 0.001$ \\
\hline Decay & Half-life (d) ${ }^{5}$ & $0-10$ & $10-100$ & $>100$ \\
\hline \multirow{2}{*}{$\begin{array}{l}\text { Wetlands/buffer } \\
\text { strips }\end{array}$} & $\begin{array}{l}\text { Ratio of area of } \\
\text { application to area of } \\
\text { buffer strip }\end{array}$ & No application & $0-100$ & $>100$ \\
\hline & $\begin{array}{c}\text { Ratio of area of } \\
\text { application to area of } \\
\text { wetland } d^{2,6}\end{array}$ & No application & $0-2500$ & $>2500$ \\
\hline $\begin{array}{l}\text { Pesticide } \\
\text { application }\end{array}$ & $\begin{array}{l}\text { Percentage of } \\
\text { recommended rate of } \\
\text { application }(\%)\end{array}$ & No application & $0-100$ & $>100$ \\
\hline $\begin{array}{l}\text { Environmental } \\
\text { sensitivity }\end{array}$ & Score from SASS $5^{7}$ & 1 & $1-15$ & 15 \\
\hline \multicolumn{5}{|c|}{$\begin{array}{l}{ }^{1} \text { Van der Werf \& Zimmer [7] } \\
{ }^{2} \text { Applied only to surface water } \\
{ }^{3} \text { Categorization for surface water; complementary score is used for groundwater } \\
{ }^{4} \text { Van Genuchten et al. [8] } \\
{ }^{5} \text { Maximum half-life of parent and daughter products is considered } \\
{ }^{6} \text { Minimum of rating for wetlands or buffer strips is used } \\
{ }^{7} \text { The sensitivity of macroinvertebrate species was rated in the South African River Health } \\
\text { Programme SASS } 5 \text { from } 1 \text { (tolerant to pollution) to } 15 \text { (intolerant to pollution) [9] }\end{array}$} \\
\hline
\end{tabular}

approximated with a straight line. Similarly, abatement costs increase as more pollution is abated. In practice, a certain level of pollution is permitted corresponding to the water quality standard. This reduces pollution to an acceptable level and also keeps pollution abatement costs within acceptable limits. In addition, farmers have other options to incorporate different means of abating pollution besides reducing pesticide usage, for example changing production practices, selecting pest tolerant crops etc. This would also shift environmental and abatement cost functions from linearity. 


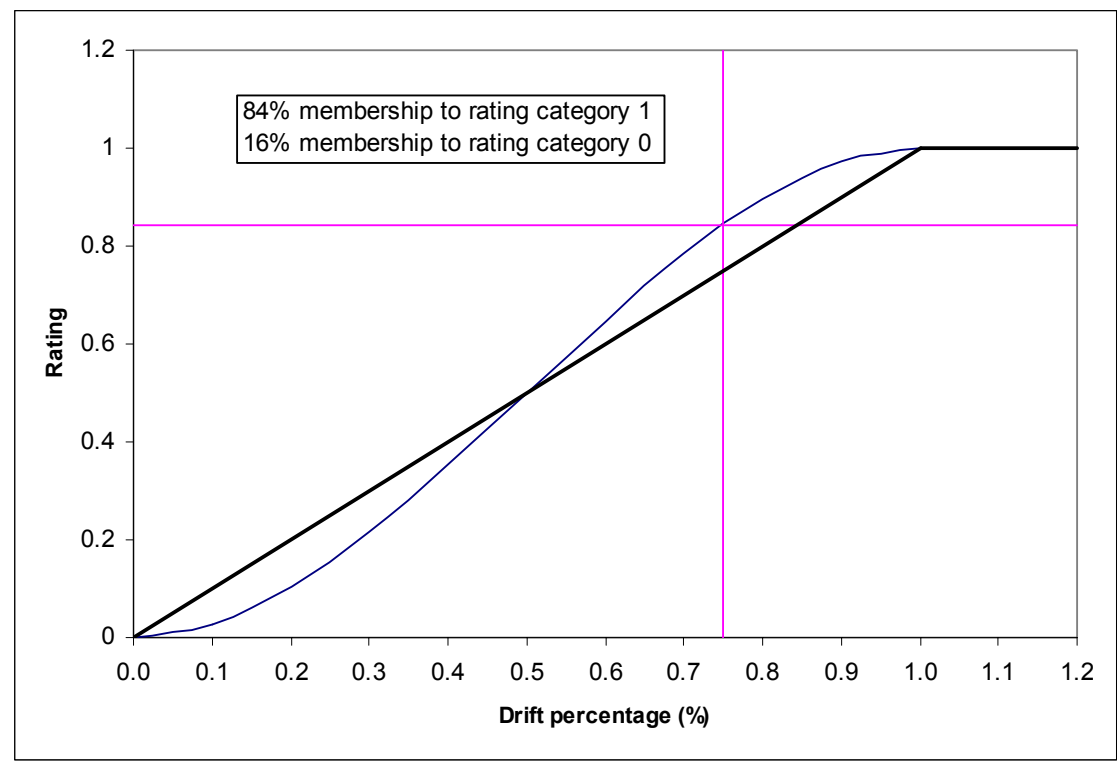

Figure 2: Example of fuzzy logic applied to rating for surface water as a function of percentage drift of pesticide at application. The curve is a Beta-cumulative distribution function used to smooth out the straight line of the fuzzy function.

Table 2: Variables and rating categorization for boolean input variables in PestEX.

\begin{tabular}{|c|c|c|c|}
\hline Input factor & \multicolumn{2}{|c|}{ Variable } & Rating categories $^{1}$ \\
\hline \multirow{2}{*}{ Flow direction } & \multirow{2}{*}{ Dominant flow } & Vertical & Minimum (0) \\
\hline & & Horizontal & Maximum (1) \\
\hline \multirow{2}{*}{ Tillage } & \multirow{2}{*}{ Tillage practice } & Yes & Minimum (0) \\
\hline & & No & Maximum (1) \\
\hline \multirow{2}{*}{ Contours } & \multirow{2}{*}{ Presence of contours } & Yes & Minimum (0) \\
\hline & & No & Maximum (1) \\
\hline
\end{tabular}




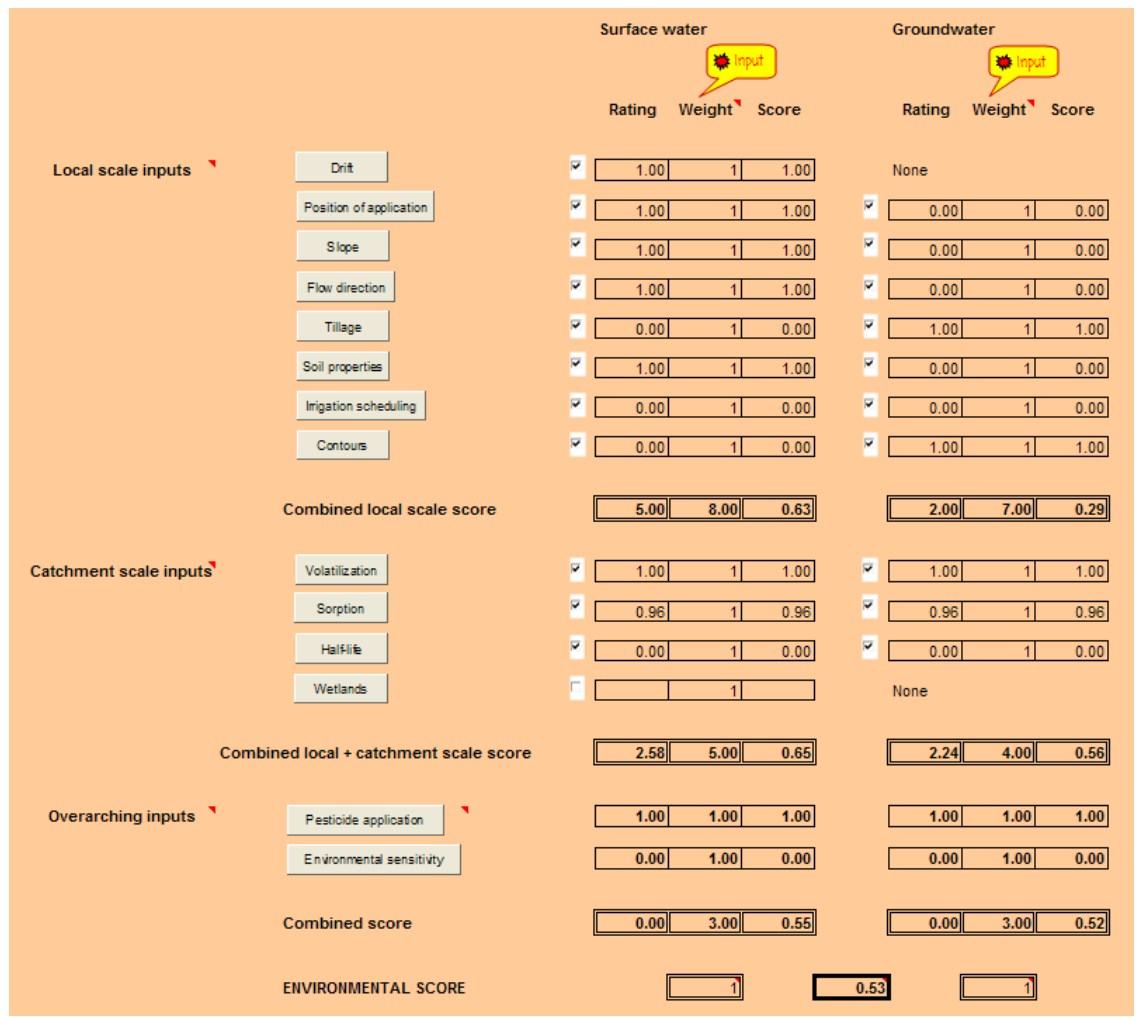

Figure 3: $\quad$ Snapshot of the Main Menu of PestEX.

\section{Example of application}

An example of application of PestEX was carried out using a case study experimental site located in the Berg river catchment (South Africa), about $5 \mathrm{~km}$ North-East of the town of Riebeek West. The experimental site was used to assess the environmental mobility of two pesticides sprayed on a 20 ha field planted to dryland wheat during the 2005 rainy winter season. A stock-watering dam adjacent to the field and groundwater were considered as target waters.

Folicur (active ingredient tebuconazole) was sprayed in solution at $30 \mathrm{~L} \mathrm{ha}^{-1}$ with an aircraft on 21 August 2005. The solution was $0.8 \mathrm{~L} \mathrm{ha}^{-1}$ of active ingredient diluted in $30 \mathrm{~L}$ of water. Methomex (active ingredient methomyl) was sprayed in solution at $30 \mathrm{~L} \mathrm{ha}^{-1}$ with an aircraft on 21 October 2005 . The solution was $200 \mathrm{~g} \mathrm{ha}^{-1}$ of active ingredient diluted in $30 \mathrm{~L}$ of water. In the few weeks following application, water samples were collected in order to measure the concentrations of the two pesticides in dam water and determine their decay rates 
(no rainfall or other dilution of dam water occurred during the sampling period). The samples were analyzed with a Gas Chromatography Mass Spectrometer (GCMS) at the Plant Protection Research Institute (PPRI) in Roodeplaat (Agricultural Research Council, Pretoria, South Africa).

A drift percentage of $2 \%$ was entered corresponding to maximum rating due to pesticide application by aircraft. A minimal distance from stream was entered because the area of application surrounds the stock-watering dam. Average groundwater depth measured in nine observational boreholes at the site is $>30 \mathrm{~m}$ corresponding to minimum rating. The average slope in the catchment is about $10 \%$ corresponding to maximum rating for surface water and minimum rating for groundwater. Whilst water in the dam originates both from overland flow and throughflow during the rainy winter season, vertical conductance is limited by shallow soils (often less than $0.5 \mathrm{~m}$ deep and predominantly loams and clays) overlying a relatively impervious Proterozoic marine deposit of Malmesbury shales. Dominant flow in the soil is therefore horizontal along the slope. Land was shallow-cultivated to break up the surface crust and enhance infiltration (shallow tillage). A minimum rating for tillage was considered for surface water, and a maximum rating for groundwater. A very low saturated hydraulic conductivity of $0.001 \mathrm{~m} \mathrm{~d}^{-1}$ was entered due to the geological nature and compaction of the soil, and based on field measurements [11]. This corresponded to maximum rating for surface water and minimum rating for groundwater. Overland flow was about $15 \%$ of annual rainfall $(300 \mathrm{~mm})$, based on measurements at Wischmeier runoff plots installed in the field [11]. It was assumed that minimal deep percolation occurs under dryland conditions, given the impermeable layer in the soil and depth of groundwater. The presence of anti-erosion contours resulted in a maximum rating for groundwater and a minimum rating for surface water for this factor.

Henry's Law constant and the organic carbon partition coefficient for methomyl were obtained from the PestEX database of chemical properties [10]. The degradation rate constants calculated from measurements taken in the stockwatering dam were $0.0293 \mathrm{~d}^{-1}$ for tebuconazole and $0.1561 \mathrm{~d}^{-1}$ for methomyl. This yielded half-lives of $23.6 \mathrm{~d}$ for tebuconazole and $4.4 \mathrm{~d}$ for methomyl. No wetlands/buffer strips were present, so this factor was disabled. Pesticide application rate was equal to the recommended rate. The rating for environmental sensitivity was not considered as the stock-watering dam is not a natural feature.

The output scores produced by PestEX were summarized in table 3 for all factors. All weightings were equal to 1 in this example. Given all factors and conditions in the field were the same for the two pesticides, the output changed depending only on pesticide properties. The model predicted moderately high mobilities of these two pesticides in relation to the receiving water bodies, mainly due to the pesticides' properties (low volatilization and sorption). A slightly higher score was calculated for tebuconazole compared to methomyl due to the different sorption coefficients and half-lives. The score for surface water was greater compared to groundwater for both pesticides. 
Table 3: $\quad$ Scores produced by PestEX in the comparative analysis of pesticide mobility.

\begin{tabular}{|c|c|c|c|c|}
\hline \multirow{2}{*}{ Factors } & \multicolumn{2}{|c|}{ Methomyl } & \multicolumn{2}{c|}{ Tebuconazole } \\
\cline { 2 - 5 } & $\begin{array}{c}\text { Score for } \\
\text { surface } \\
\text { water }\end{array}$ & $\begin{array}{c}\text { Score for } \\
\text { groundwater }\end{array}$ & $\begin{array}{c}\text { Score for } \\
\text { surface } \\
\text { water }\end{array}$ & $\begin{array}{c}\text { Score for } \\
\text { groundwater }\end{array}$ \\
\hline Drift & 1 & - & 1 & - \\
\hline Position of application & 1 & 0 & 1 & 0 \\
\hline Slope & 1 & 0 & 1 & 0 \\
\hline Flow direction & 1 & 0 & 1 & 0 \\
\hline Tillage & 0 & 1 & 0 & 1 \\
\hline Soil properties & 1 & 0 & 1 & 0 \\
\hline $\begin{array}{c}\text { Irrigation } \\
\text { scheduling/rainfall } \\
\text { distribution }\end{array}$ & 0 & 0 & 0 & 0 \\
\hline Contours & 0 & 1 & 0 & 1 \\
\hline $\begin{array}{c}\text { Combined local scale } \\
\text { score }\end{array}$ & $\mathbf{0 . 6 3}$ & $\mathbf{0 . 2 9}$ & $\mathbf{0 . 6 3}$ & $\mathbf{0 . 2 9}$ \\
\hline Volatilization & 1 & 1 & 1 & 1 \\
\hline Sorption & 0.96 & 0.96 & 1 & 1 \\
\hline Half-life & 0 & 0 & 0.06 & 0.06 \\
\hline Wetlands & - & - & - & - \\
\hline $\begin{array}{c}\text { Combined local scale }+ \\
\text { catchment scale score }\end{array}$ & $\mathbf{0 . 6 5}$ & $\mathbf{0 . 5 6}$ & $\mathbf{0 . 6 7}$ & $\mathbf{0 . 5 9}$ \\
\hline Pesticide application & 1 & 1 & 1 & 1 \\
\hline Environmental sensitivity & - & - & - & - \\
\hline Combined score & $\mathbf{0 . 8 3}$ & $\mathbf{0 . 7 8}$ & $\mathbf{0 . 8 4}$ & $\mathbf{0 . 8 0}$ \\
\hline Environmental score & & $\mathbf{0 . 8 0}$ & & $\mathbf{0 . 8 2}$ \\
\hline
\end{tabular}

\section{Conclusions}

A pesticide environmental mobility index was developed that accounts for the main factors having an effect on the contamination of surface- and groundwater, including the effects of mitigation/management measures. It should be noted that PestEX gives a normalized environmental index based on several input variables. Absolute values of contamination will depend on the total amounts of pesticide applied and the dilution capacity of the receiving water body. These can be obtained through measurements, and/or predicted with transfer functions and process models.

Similar indicators of pesticide environmental impact have been developed worldwide and they are applied for different purposes. The advantages of PestEX compared to other indicators are the tiered approach in the combination of factors (local scale, catchment scale and overarching level), the inclusion of mitigation/management measures and the possibility of linkages to economic models. Additional factors can be easily incorporated in the programme, for example solubility of chemicals or effects on air quality, providing some 
information is available on the behaviour of chemicals in the environment and depending on the specific objectives to be achieved.

It is envisaged that potential users could be the scientific community, farmers, pesticide consultants and the regulatory authority. Many applications are possible, but the main ones are envisaged to be comparative analyses of mobility and exposure potential (between two or more pesticides or factors), and sensitivity analyses (effects of changing one or a combination of factors). In particular, applications can be the comparison of environmental and pollution abatement costs of different chemicals for regulatory or marketing purposes, sensitivity analyses to assess the effects of different mitigation/management measures (e.g. size of wetlands to be constructed), the minimization of costs by changing mitigation/management practices etc. For all purposes, a calibration of the model is recommended by adjusting the weighting of each factor, and comparing the output to measured data. The sensitivity of PestEX should be calibrated and tested at different sites and for different pesticides.

\section{Acknowledgements}

The authors acknowledge the Water Research Commission (Pretoria, South Africa) for funding, the project team and the Reference Group of Water Research Commission project No. K5/1516.

\section{References}

[1] Cullis, J., First Order Estimate of the Contribution of Agriculture to NonPoint Source Pollution in South Africa, Report on the project Modelling Non-Point Source Pollution in Agriculture from Field to Catchment Scale: A Scoping Study, Water Research Commission Report No. K5/1467: Pretoria, South Africa, 2004.

[2] Vanclooster, M., Boesten, J.J.T.I., Trevisan, M., Brown, C.D., Capri, E., Eklo, O.M., Gottesburen, B., Gouy, V. and Van der Linden, A.M.A., A European test of pesticide-leaching models: methodology and major recommendations. Agricultural Water Management, 44, pp. 1-19, 2000.

[3] Boesten, J.J.T.I., From laboratory to field: uses and limitations of pesticide behaviour models for the soil/plant system. Weed Research, 40, pp. 123-138, 1999.

[4] Van der Werf, H.M.G. \& Petit, J., Evaluation of the environmental impact of agriculture at the farm level: A comparison and analysis of 12 indicator-based method. Agriculture Ecosystems and Environment 93(13), pp. 131-145, 2002.

[5] Reus, J., Leendertse, P., Bockstaller, C., Fomsgaard, I., Gutsche, V., Lewis, K., Nilsson, C., Pussemier, L., Trevisan, M., Van der Werf, H., Alfarroba, F., Blumel, S., Isart, J., McGrath, D. \& Seppala, T., Comparison and evaluation of eight pesticide environmental risk indicators developed in Europe and recommendations for future use. Agriculture Ecosystems and Environment, 90(2), pp. 177-187, 2002. 
[6] Zadeh, L.A., Fuzzy sets. Inform. Control, 8, pp. 338-353, 1965.

[7] Van der Werf, H.M.G. \& Zimmer, C., An indicator of pesticide environmental impact based on a fuzzy expert system. Chemosphere, 36(10), pp. 2225-2249, 1998.

[8] Van Genuchten, M.Th., Leij, F.J. \& Yates, S.R., The RETC Code for Quantifying the Hydraulic Functions of Unsaturated Soils, Version 1.0, EPA Report 600/2-91/065, U.S. Salinity Laboratory, USDA, ARS: Riverside, California, 1991.

[9] Dickens, C.W.S. \& Graham, P.M., South African Scoring System (SASS) Version 5: Rapid bioassessment method for rivers. African Journal of Aquatic Science, 27(1), pp. 1-10, 2002.

[10] Usher, B., Pretorius, J.A., Dennis, I., Jovanovic, N., Clarke, S., Cave, L., Titus, R. \& Xu, Y., Identification and Prioritization of Groundwater Contaminants and Sources in South Africa's Urban Catchments. Water Research Commission Report No. 1326/1/04: Pretoria, South Africa, 2004.

[11] Fey, M.V., De Clercq, W.P. \& Jovanovic, N., Land Use Impacts on Salinity in Western Cape Waters. Water Research Commission project No. K5/1503: Pretoria, South Africa, 2009. 